\title{
Águas de Dançar Juntos: Coordenação e Sintonização Multiespécies na Pesca com os Botos em Laguna ( SC - Brasil)
}

\author{
Brisa Catão ${ }^{1}$ \\ ${ }^{1}$ Universidade Federal de Minas Gerais, Belo Horizonte, MG, Brasil
}

\section{Resumo}

O artigo dedica-se à pesca conjunta que acontece na cidade de Laguna (Santa Catarina, Brasil). A pesquisa narra uma história de encontros entre tainhas em migração pela Costa Sul brasileira, golfinhos nariz-degarrafa que habitam a Lagoa Santo Antônio dos Anjos e pescadores artesanais. Os golfinhos e os pescadores que participam dessa pesca vêm desenvolvendo conjuntamente formas de convivência, colaboração e bem viver. Bôtas boas e botos bons, como são conhecidos os animais que participam da pesca, conduzem cardumes de tainhas na direção dos pescadores e sinalizam a localização dos peixes com movimentos corporais característicos. Os pescadores reconhecem individualmente cada boto bom e bota boa, atribuemlhes nomes, descrevem seus hábitos particulares de pesca e outras características de suas histórias de vida, como relações de parentesco, desaparecimentos temporários e episódios de emalhe. O texto aborda formas de comunicação ligadas às ideias de atração, corpos, movimentos, corresponsividades, temporalidades humanas e não humanas, ajustamentos rítmicos, coordenação e sintonização multiespécies. Analisando o desenvolvimento de habilidades interespecíficas, o texto explora complementarmente os conceitos de etnoetologia, etoetnologia e etoecologia.

Palavras-chave: Pesca. Relações Multiespécies. Golfinho Nariz-de-Garrafa. Tainha.

\section{Waters for Dancing Together: Coordination and Multispecies Tuning in Dolphin Fishing in Laguna ( SC - Brazil)}

\begin{abstract}
This article is dedicated to conjoint fishing that occurs in the city of Laguna (Santa Catarina, Brazil). The research tells a story of encounters between mullets migrating along the Brazilian south coast, bottlenosed dolphins that inhabit Lagoa Santo Antônio dos Anjos and fishermen. Dolphins and fishermen that participate in conjoint fishing have been jointly developing forms of coexistence, collaboration and good living. Good botas and good botos guide schools of mullets towards the fishermen and signal the location of the fish with characteristic body movements. Fishermen recognize individually each good dolphin, assign names to them, describe their particular habits and other characteristics of their life stories, such as kinship relationships, temporary disappearances and gill episodes. The text addresses forms of communication linked to the ideas of attraction, bodies, movements, co-responsiveness, human and non-human temporalities, rhythmic adjustments, coordination and multispecies attunement. Analyzing the development of interspecific skills, the text further explores the concepts of ethno-ethology, etoethnology and eto-ecology.
\end{abstract}

Keywords: Fishing. Multispecies Relations. Bottlenose Dolphin. Mullet. 
Tudo que vive inspira e expira, individual e coletivamente. É assim que as plantas dançam,é assim que dançam as pedras. Dançam, sem qualquer paranoia da aparência, sem qualquer teatro da encenação, sem qualquer movimento mutilado por uma moral qualquer. Dançam como dançam as crianças, antes dos pais. Dançam, libertas do corpo-frase-feita.

(BITARÃES, 2021, no prelo)

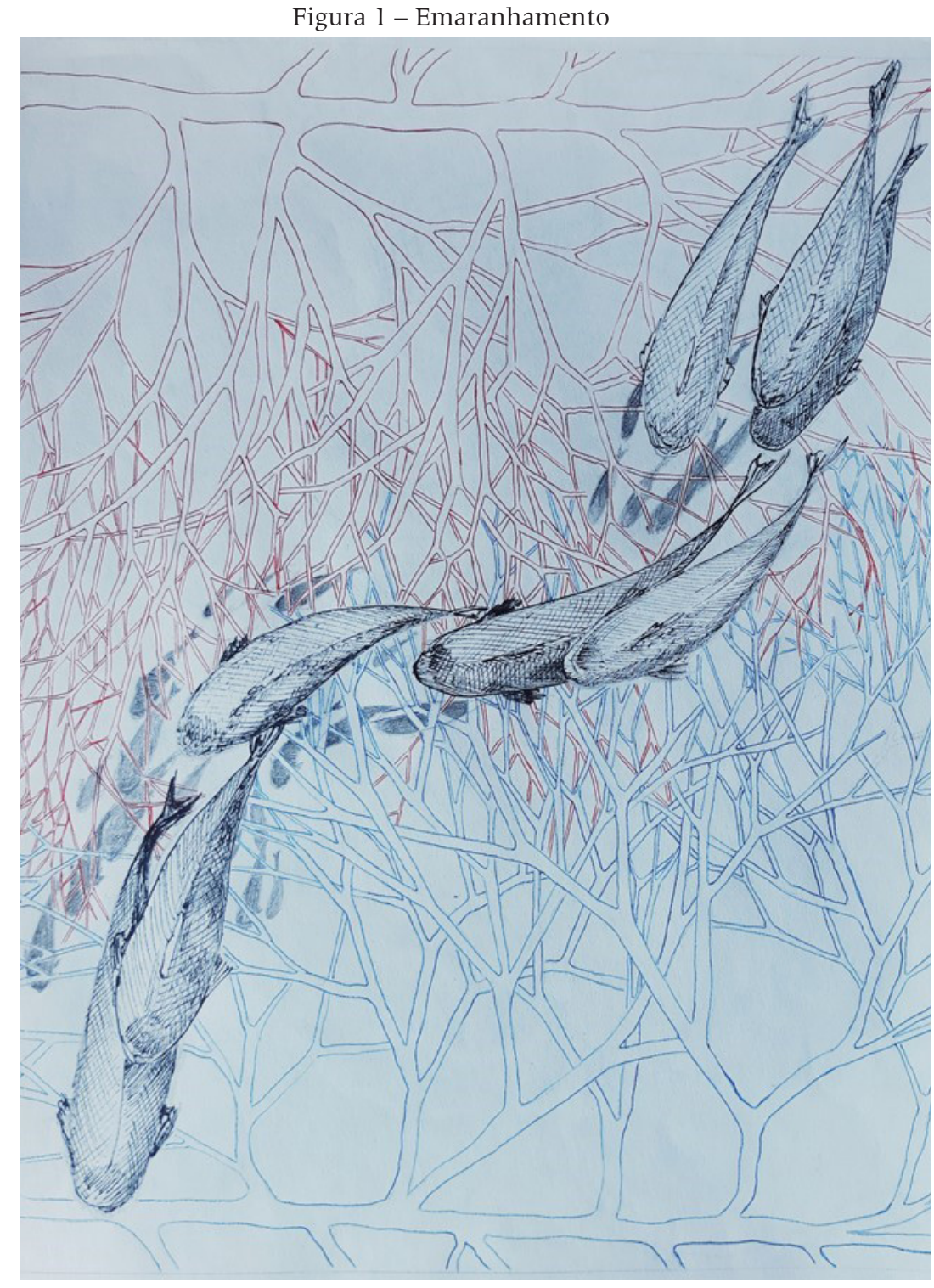

Fonte: Elaborada por David Arranhado 


\section{Os Botos da Laguna}

$\mathrm{C}$ omo toda etnografia, a pesquisa em Laguna narra uma história de encontros. Encontros entre peixes, botos, pescadores, redes de pesca, pedras, ventos, fluxos d'água e uma certa lagoa. A história envolve, principalmente, tainhas em migração pela Costa Sul brasileira, golfinhos nariz-de-garrafa que habitam a Lagoa Santo Antônio dos Anjos e pescadores que nasceram na cidade de Laguna, SC. Ela almeja ser uma história sobre coabitação, habilitação interespecífica e socialidade corporificada entre espécies.

Há pelo menos 170 anos, os ascendentes daqueles pescadores artesanais e daqueles botos bons e bôtas boas ${ }^{1}$, como são carinhosamente conhecidos os golfinhos que participam da pesca, vêm desenvolvendo conjuntamente formas de convivência, colaboração e bem viver. Aliaram-se em torno de alguns projetos comuns: capturar tainhas e se relacionar certamente são alguns deles. Bôtas boas e botos bons conduzem cardumes de tainhas na direção dos pescadores e, no momento certo, sinalizam a localização dos peixes com movimentos corporais característicos. "O boto bom traz o peixe para o pescador", dizem esses tarrafeadores e outros moradores da cidade. Os pescadores conhecem muito bem os animais que colaboram com eles. O tamanho do animal, a coloração, o formato da galha (como é chamada a nadadeira dorsal), as marcas nessa nadadeira e pelo corpo, além de certos movimentos e comportamentos específicos, são as principais formas de reconhecimento. Os pescadores reconhecem individualmente cada boto bom e bôta boa. Atribuem-lhes nomes, descrevem seus hábitos particulares de pesca e outras características de suas histórias de vida, como relações de parentesco, desaparecimentos temporários e episódios de emalhe. Surgiram daí fortes parcerias de trabalho e laços interespecíficos de amizade, que alguns deles nutrem por mais de 30 anos. Quando questionados sobre os golfinhos que não trabalham na pesca, a resposta dos pescadores costuma ser: "ah, isso aí é boto ruim!", sem maiores considerações. Botos ruins, vadios ou turistas, assim são conhecidos os animais que não se engajam na pesca² ${ }^{2}$.

Datas precisas a respeito de quando essa cooperação começou são difíceis de estimar. Não há muita informação disponível sobre a origem e a história da pesca conjunta ou

\footnotetext{
Termos e expressões locais surgem em itálico ao longo do texto. Na norma culta da língua portuguesa, a palavra "boto" é um substantivo epiceno, ou seja, não flexiona gênero. A desambiguação de gênero é feita pela aposição das palavras "macho" e "fêmea", que não precisam concordar com os apostos. Estão gramaticalmente corretas, por exemplo, as expressões "boto-fêmeo" ou "boto-fêmea". No entanto, tais vocábulos me parecem excessivamente masculinizantes, além de não fazerem jus à poética presente nas expressões dos pescadores, "bota" e "bota boa". A homografia com a palavra que designa as botas de calçar faz com que as golfinhos fêmeas de Laguna sejam lidas (e, portanto, imaginadas) como o calçado. Por isso, optei por acentuar e criar o neologismo bôta. Agradeço imensamente todas as cuidadosas considerações de Heloísa Souza sobre linguagem inclusiva de gênero.

2 A estimativa, em 2011, é que do total desta população residente, entre 50 e 60 animais, cerca de 25-27 são bôtas e botos bons, ou golfinhos "cooperativos", conforme a terminologia biológica (DAURA-JORGE, 2011, p. 9). Em 2015, os pescadores na Tesoura estimaram 17 animais. Golfinhos nariz-de-garrafa (Tursiops truncatus) podem viver tanto em pequenos agrupamentos costeiros e serem fiéis ao seu local de residência, como é o caso em Laguna, quanto em grandes grupos oceânicos e transeuntes (DAURA-JORGE, 2011, p. 22). Embora existam evidências de que os botos de Laguna cheguem às cidades de Araranguá, Torres, Tramandaí, Lagoa dos Patos (ao Sul) e baía de Guaratuba (ao Norte), eles possuem um padrão de residência bem definido, marcado pela alta fidelidade ao local (SIMÕES-LOPES; FÁBIAN, 1999; SIMÕES-LOPES; DAURA-JORGE, 2008). Agrupamentos populacionais de Tursiops truncatus podem variar desde agrupamentos de 30 indivíduos - como no estuário do Sado, em Portugal - àqueles com mais de 7 mil, como registrado no Noroeste do Mediterrâneo (DAURA-JORGE, 2011).
} 
cooperativa ${ }^{3}$ em Laguna. O que se sabe é que essa cidade ocupa um território com uma longa história de ocupação e coabitação. Existem vestígios de ocupação humana na região há pelo menos 6.000 anos (CADORIN; CADORIN, 2013, p. 8). Seus primeiros habitantes foram povos sambaquieiros ${ }^{4}$. Em Santa Catarina, exatamente no litoral de Garuva, São Francisco do Sul e Laguna, estão alguns dos maiores sambaquis do mundo - alcançam até 30 metros de altura por centenas de metros de comprimento. Como é de se imaginar, esses povos nunca estiveram sozinhos. Em todos os grandes sambaquis, além de esqueletos humanos, encontram-se outras evidências de ocupação, como carvão, cinzas, restos de fogueiras, ossos de peixes, aves e mamíferos, ossadas de baleias (muitas vezes, parcialmente carbonizadas), pinças de crustáceos, cascas de tartaruga, espinhos de ouriços do mar (ROHR, 1984, p. 79).

Junto aos esqueletos humanos sepultados nesses locais foi encontrado um vasto material na forma de oferendas funerárias e adornos pessoais, como: machados de pedra, pontas de flecha ósseas, conchas, ossos de baleias e dentes de mamíferos (ROHR, 1984, p. 79). Pequenos pilões de pedra, caprichosamente polidos na forma de animais, também foram encontrados nos sambaquis. Chamados zoólitos, tais artefatos zoomorfos representam parte da escultura pré-histórica (ROHR, 1984). Há relatos de que uma estatueta como esta, em forma de golfinho, foi encontrada em uma urna funerária em Laguna (informação obtida por meio de comunicação pessoal, em 2015, de Pedro Volkmar Castilho). Claro que isso não significa, necessariamente, que botos e pescadores já pescavam juntos naquela época, mas indica, indubitavelmente, que botos e pescadores vivem e morrem juntos, naquela região, desde aquela época.

Nas falas dos pescadores de Laguna, a presença dos golfinhos e a convivência com esses animais soa imemorial. Parece até ocupar um tempo mítico, em que acontece desde que o mundo é mundo. "Quando descobriram isso aqui já tinha boto. Os botos, acho que eles já nasceram aqui dentro da Lagoa" (LATINHA apud BOCCHINO, 2015, min 6:20. "Desde que eu me entendo por gente já convivia com a pesca no boto. Pescava outro tipo de pesca, mas já pescava no boto naquela época, quando eu era guri" (SEU GUERRINHA apud BOCCHINO, 2015, min. 6:40). O primeiro artigo sobre o tema menciona um registro da cidade que data o início da pesca em 1847 (PRYOR et al., 1990, p. 325). A estimativa mais recente reforça a informação de que ela já existia naquela época. De acordo com o biólogo e pesquisador Pedro Volkmer Castilho, uma senhora nascida por volta de 1903

\footnotetext{
"Pesca cooperativa" é o modo como o fenômeno é amplamente designado na literatura biológica - ver, por exemplo, Pryor et al. (1990), Simões-Lopes (1991), Simões-Lopes, Fábian e Menegueti (1998), Simões-Lopes, Daura-Jorge e Cantor (2016), Peterson (2005), Peterson, Hanazaki e Simões-Lopes (2008), Daura-Jorge (2011) e Romeu (2012; 2015). A opção pela designação "pesca conjunta", ao invés de "cooperativa", relaciona-se com o fato de que "cooperação", nesta expressão, detém um sentido derivado das formas canônicas de classificação das interações ecológicas - predação, simbiose, cooperação, parasitismo, mutualismo etc. Classificação esta que parece guardar de fundo a pergunta sobre quem ganha, ou se beneficia, e quem perde, ou se prejudica, com a associação em questão. Claro que há bons motivos para se fazer tal pergunta. Entretanto, classificar uma série de relações entre os mais diferentes tipos de seres, a partir dos "custos e benefícios" dessas associações para os organismos envolvidos, me parece uma forma um tanto utilitarista de conceber tais relações. Na tentativa de descolar de afastar o sentido de cooperação ou colaboração dessa herança utilitária e economicista, optamos por "pesca conjunta" (CATÃO; BARBOSA, 2018). Para uma discussão mais detalhada sobre esse ponto, ver Catão (2019), em especial a conclusão do trabalho.

4 Sambaqui é um nome de origem guarani que significa "monte de conchas" (tambá: concha; Ki: monte cônico). Tais formações podem também ser chamadas casqueiros, concheiros, berbigueiros, ostreiras ou sernambis (ROHR, 1984, p. 78).
} 
contara que o avô dela já tarrafeava com os botos em Laguna (informação obtida por meio de comunicação pessoal, em maio de 2015, de Pedro Volkmer Castilho).

Em uma pequena reportagem no folhetim $O$ Pharol, o falecido pescador Dido Morais (2004) discorre sobre os botos antigos da Laguna e esboça algumas notas sobre seus nomes, características e relações de parentesco. Dido menciona três marcos temporais: a década de 1930, de 1950 e os botos vivos e atuantes na ocasião da reportagem.

Os pescadores mais antigos dizem que por volta de 1930 já existiam botos velhos como: Judeu, Fandango, Chinelo, Rampeiro, Aluminio, Cego, Boto Branco, Crise Grande, Crise Pequeno. Daí para diante, os botos foram se multiplicando. Vieram Miranda, Gaivota, Latão, Gavião, Tangará, Dolores, Pombo, Tibio. A partir da década de 50, os botos mais antigos foram desaparecendo misteriosamente e surgindo os mais novos, como Galha Torta, Galha Cortada, Marusca, Prego, Riscadeira, Juscelino, Lata Velha, Bate Cabeça, Inrilha, Tramandai. Hoje [2004], somente 22 botos trabalham nos pontais junto aos pescadores, são eles: Caroba, Avalanche, Scooby, Chega Mais, Mandala, Cabide, Botinha do Rio, Figueiredo, Indio, Ligeirinho, Pirulito, Andorinha, Táxi, Borracha, Araranguá, Isaura, Meleca, Sacolão, Botinha do 19 e Princesa.

Nesse mesmo registro, Dido conta sobre as características de alguns desses animais e a origem de alguns dos nomes de bôtas e botos antigos da Laguna.

Aluminio era um boto muito claro, assim como o Boto Branco. O Gavião costumava rasgar as tarrafas para roubar os peixes. Já o Galha Torta tinha a galha [nadadeira dorsal] ligeiramente voltada para o lado. Marusca era uma marca de cigarro da época, Juscelino era o presidente do Brasil. Inrilha era uma gíria para quando alguém não gostava de alguma coisa. Dizia-se: "não é assim e não inrilha". Caroba, por ser um boto muito escuro, lembrava uma madeira do mesmo nome. Taffarel foi uma homenagem ao goleirão do tetra. Avalanche é um boto muito arrojado quando cerca o peixe, assim como o Ligeirinho. Scooby lembra o personagem do desenho. Chega Mais e Mandala nasceram quando a Rede Globo estava passando novelas. Sacolão só trabalha quando quer. Rampineli, [foi] batizado pelos pescadores por gratidão a um fazendeiro da região chamado Aldo Rampineli. Táxi percorre diariamente todos os pontos de pesca, mas não fica por muito tempo em nenhum. Princesa, por ser um boto muito bonito ${ }^{5}$ e Pirulito por ser o mais feinho da Lagoa (Dido Morais, 2004).

Figura 2 - Botos na Cidade

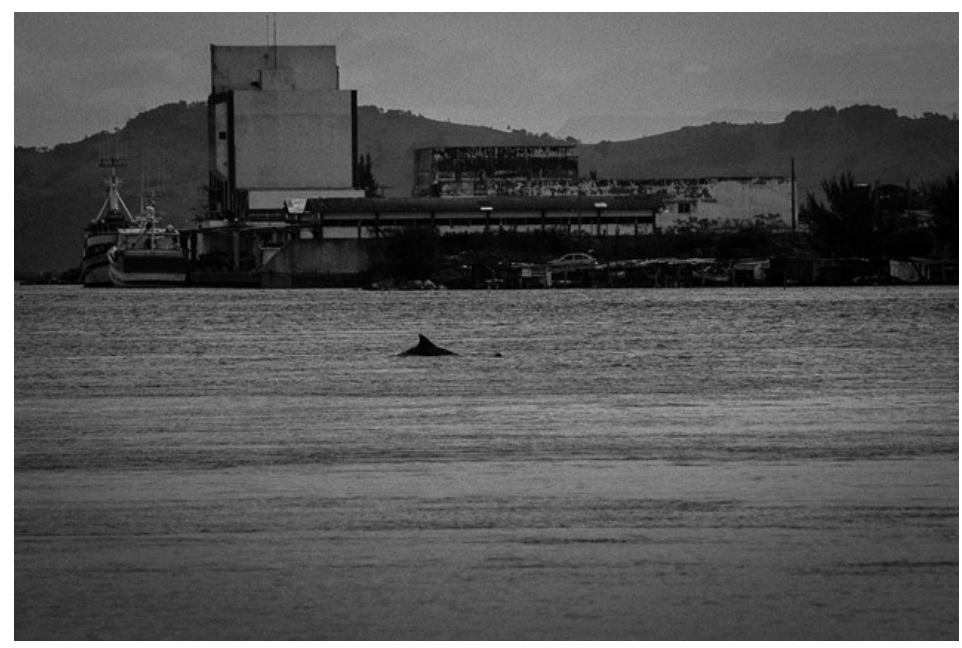

Fonte: Acervo pessoal de Brisa Catão

5 É comum os pescadores não flexionarem número e gênero quando o assunto são os botos e as tainhas. Na maioria das vezes, dizem o boto e o peixe. Podem se referir ao "boto", no masculino, mesmo quando o assunto é procriação e cuidados com os filhotes. 
Ao longo dos anos, pescadores e golfinhos têm sido criativos em suas formas de colaboração. Desenvolveram técnicas diferentes, com artefatos também diferentes (embarcados ou não), em diversos pontos de pesca na cidade. Todos eles, contudo, ligados à Lagoa Santo Antônio dos Anjos. Ao longo de suas margens e águas - em prainhas, sarilhos ${ }^{6}$, esperas no meio da Lagoa e na foz do rio Tubarão - estão distribuídos cerca de 25 pontos de pesca com os botos. Em alguns deles, os homens pescam em pequenas canoas, em outros pescam por terra. Isto é, sem o uso de embarcações, mas, muitas vezes, com os corpos dentro d'água. Suas redes são, invariavelmente, as tarrafas. Os botos bons e as bôtas boas podem mostrar o peixe no salto ou na batida.

Neste texto, falaremos sobre a pesca no pulo ou salto do boto, que acontece no ponto de pesca chamado Tesoura. A batida, outra técnica de pesca com os botos em Laguna, hoje acontece apenas na foz do rio Tubarão. Os procedimentos diferem daqueles da pesca no salto do boto, no que tange ao uso de embarcações, à organização dos pescadores e à movimentação dos botos no cerco ao cardume7. Na batida, os botos “circulam o cardume" e "vêm ajuntando o peixe bem na frente da canoa do meio, deixam ele ali bem presinho" (informação obtida por meio de comunicação pessoal, em maio de 2016, de Amilton), para então sinalizar o momento oportuno para o lançamento das tarrafas. “O boto faz a volta no cardume e passa de lado, às vezes, com a cola [nadadeira caudal] e a barriguinha para cima. Lá na batida o boto falta colocar o peixe com a mão dentro da canoa!" (informação obtida por meio de comunicação pessoal, em maio de 2016, de Amilton ).

Na Tesoura, o boto bom aperta ou tranca o peixe para o pescador. Na sequência, ele mostra o peixe no salto. Os pescadores que ali se reúnem são homens que sabem tarrafear no boto. A concentração de tarrafeadores depende da época do ano e das condições de pesca. Já vi apenas três ou quase 60 pescadores na Tesoura. Na linha d'água, perfilados com a água na altura da cintura ou do peito, os pescadores formam um anteparo. Por isso, o boto tranca ou aperta o peixe. Com as tarrafas enroladas e suspensas nas mãos, eles aguardam um sinal.

Sarilhos são armações nas margens, ou mesmo dentro da lagoa, que funcionam como pequenos cais e/ou "garagens" suspensas para pequenas embarcações. Funcionam como uma espécie de transição ou passagem da cidade para a lagoa e vice-versa.

7 Na batida, três canoas posicionam-se uma ao lado da outra. A canoa do meio é chamada de batida (é a canoa da vez, que tem prioridade para tarrafear); a da frente é chamada de cabeça e a última de cola ou revés. A cabeça e a cola tarrafeiam cobrindo ou fazendo o recurso. Isto é, depois que o pescador na canoa do meio lançou sua rede, os pescadores das outras duas canoas podem tarrafear para tentar capturar os peixes que, eventualmente, tenham escapado. 


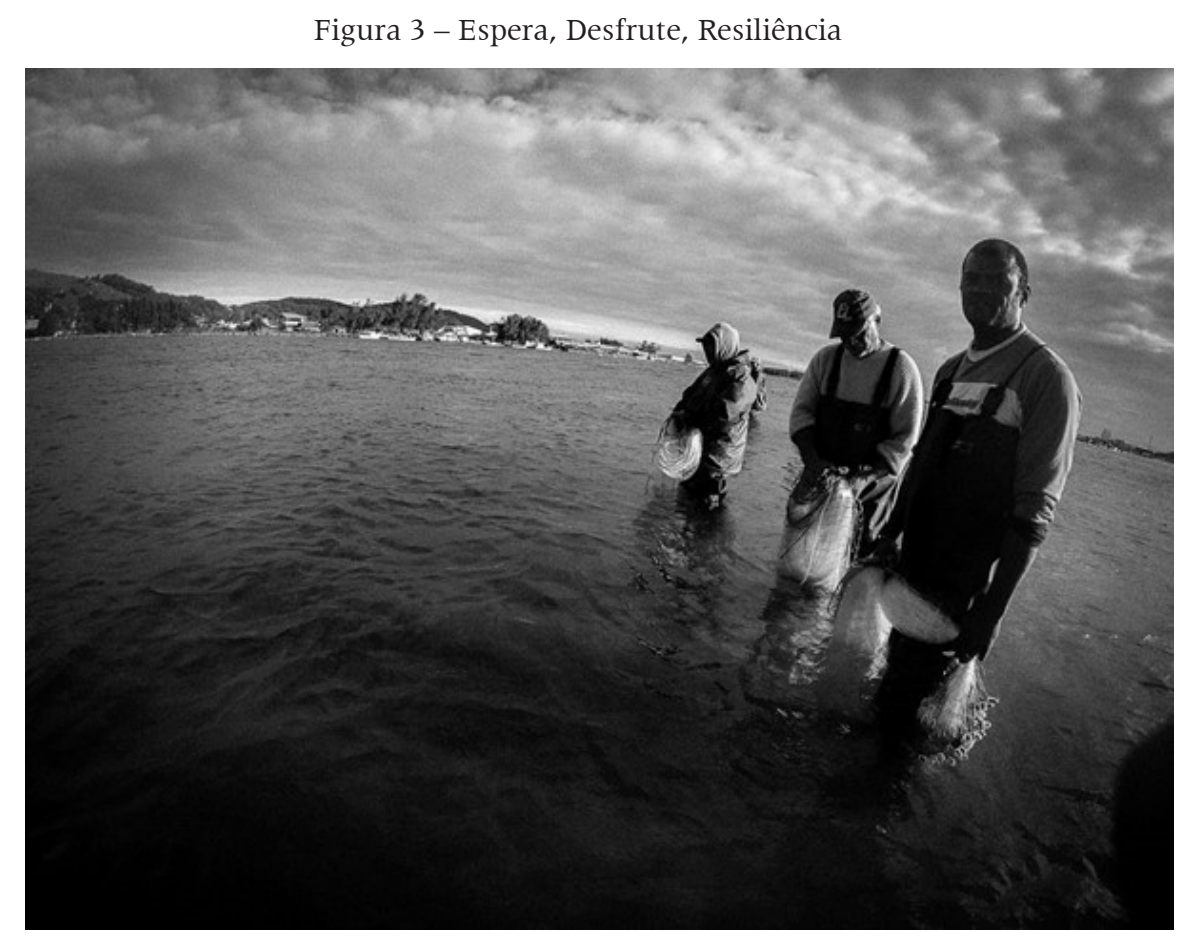

Fonte: Acervo pessoal de Brisa Catão

Embora os golfinhos visitem a Tesoura diversas vezes ao longo de um dia, as jornadas e a espera dos tarrafeadores podem ser extenuantes. As condições costumam ser severas: a água é fria ou gelada, ventos fortes, chuvas, variações de temperatura e incidência solar atravessam a estação, tornando indispensáveis o uso de bonés, chapéus, toucas de lã, capas de chuva, roupas de neoprene e, sobretudo, o macacão impermeável com botas de borracha acopladas, que possibilitam que os pescadores permaneçam na água por longos períodos. Fora d'água, outros homens limpam e vendem peixes, fazem ou reparam tarrafas ou, simplesmente, esperam sua vez de fazer a vaga, que são as posições dentro d'água ocupadas por ordem de chegada no local.

Quando os botos aparecem, em duplas, trios, grupos ou sozinhos, o ritmo local muda. A atmosfera de espera e de descontração assume uma aura de ação ligeiramente apreensiva. Posicionados dentro d'água, os pescadores acompanham atentamente o lanço, cujo desfecho nunca é completamente previsto.

Diferente de outras situações de interações com golfinhos, os pescadores em Laguna não batem remos ou varas na água, não atraem os golfinhos com instrumentos musicais, não lhes oferecem peixes ou tentam tocá-los. Com o propósito de chamar a atenção das bôtas e dos botos bons, os pescadores podem bater a tarrafa na água. A rede possui uma chumbada em sua extremidade que produz reverberações na água. Os golfinhos possuem uma apurada sensibilidade acústica e tátil. Não sentem cheiros, mas enxergam e escutam muito bem. Como bem pontua Herzing (2013, min. 3:8), "The dolphins are natural acousticians". Comunicam-se por posturas corporais, por uma infinidade de sons, além de possuírem muita sensibilidade tátil. "Se é o boto que trabalha para gente, então a gente bate com a tarrafa na água, ele escuta, vem aqui para ver se tem o peixe". Esse recurso é utilizado para chamar a atenção do animal em momentos adequados. Caso 
contrário, pode espantar o boto ou a bôta em questão e colocar tudo a perder. Alguns pescadores dizem que bater a tarrafa na água cumpre também a função de assustar o peixe. Faz ele correr, viajar, se movimentar. Ou seja, o gesto pode ter por finalidade influenciar a movimentação tanto dos botos quanto das tainhas.

Sempre em movimento, entre mergulhos e reaparições intermitentes, os botos submergem, desaparecem nas águas turvas do canal e voltam a emergir poucos ou muitos metros adiante. Os pescadores acompanham os botos atentamente, procurando antever onde ressurgirão a cada vez. Da areia e da linha d'água, a maior parte do tempo seguimos seus deslocamentos observando as nadadeiras dorsais e os borrifos d'água lançados pelos orifícios respiratórios.

Debaixo d'água, as tainhas refugiam-se em meio às pedras no fundo e nas laterais do canal. Segundo os pescadores, às vezes, os botos atiçam as tainhas com movimentos bruscos, como batidas da nadadeira caudal na superfície da água. Mas a conduta mais comum é os golfinhos aguardarem, mantendo-se discretamente perto dos alagados (como são chamadas as aglomerações submersas de pedras), cheirando peixe, boiando de barriga para cima, disfarçando.

Quando as tainhas deixam as pedras, inicia-se o cerco. Um ou mais botos afugentam os peixes em direção à barreira formada pelos pescadores. No momento em que o cardume de tainhas encontra-se ao alcance de alguma tarrafa, o boto bom ou a bota boa faz um movimento corporal característico para mostrar peixe aos pescadores. É o momento tão esperado, quando os homens devem arremessar suas redes. O primeiro a fazê-lo é aquele na vaga em frente à sinalização do animal. Em seguida, é a vez daqueles que estão imediatamente ao seu lado lançarem as tarrafas de fora, ou do recurso, para capturar as tainhas que eventualmente escaparam. Cada sinalização de um golfinho, portanto, desencadeia uma sequência de movimentos quase coreografados de torções de troncos e estiramentos de braços para arremesso das redes. O boto que mostrou o cardume pode continuar por ali trabalhando ou ir embora lagoa adentro ou mar afora. Algum tempo depois, aqueles mesmos botos ou outros chegarão, e a captura recomeçará.

A circulação das tainhas pela Lagoa Santo Antônio dos Anjos influencia a movimentação de botos e de pescadores pelos pontos de pesca. Os pescadores possuem um vasto repertório de classificação das tainhas. Uma macroclassificação designa as tainhas como peixe de entrada e peixe de cima. O peixe de entrada são os cardumes vindos do mar grosso. Tainhas advindas do Sul, em migração pela costa, que entram na lagoa Santo Antônio dos Anjos são conhecidas como facões ou tainhas facoadas, elas são capturadas ao longo do outono e do inverno, época da "temporada das tainhas" na região. Já o peixe de cima são as tainhas que se criaram na lagoa - virotes, tainhota, o peixe miúdo - capturadas nos pontos de pesca lagoa adentro, sobretudo ao longo da primavera e do verão.

Durante o outono e o inverno (entre abril e setembro), portanto, os golfinhos estão mais concentrados na região do estuário (no canal ou Boca da Barra), em busca do peixe de entrada, enquanto ao longo da primavera e do verão eles circulam preferencialmente pelas áreas mais rasas da lagoa (SIMÕES-LOPES; FÁBIAN, 1999, p. 1.018), onde está o peixe de cima. Dessa forma, diferentes momentos no ciclo de vida das tainhas organizam a movimentação de botos e pescadores, além de técnicas, modalidades e temporadas de pesca. 
Por isso, eu discordo de Pryor et al. (1990, p. 328, tradução minha), quando eles afirmam que "[...] na pesca cooperativa na costa brasileira, a pesca é iniciada e controlada pelos golfinhos". Botos e pescadores estarão onde as tainhas estiverem. A movimentação das tainhas, por seu turno, é correlacionada aos fluxos e intensidades de ventos, correntes e marés. Os movimentos das marés se correlacionam com as fases da lua. E, assim, indefinidamente. Portanto, não há uma única fonte de agência, mas movimentos e ações que engendram outros movimentos e ações. Configura-se, portanto, uma situação de pluriagentividade, em que a agência deixa de estar concentrada nos humanos, nos golfinhos ou mesmo nos peixes, e passa a ser percebida como algo distribuído em um dado ambiente. Agência e controle, portanto, são sempre mais difusos do que podem parecer à primeira vista (LATOUR, 2013; 2015). O “ator" (humano e outro-que-humano), nesse sentido, é semelhante ao ator-rede latouriano: "[...] não é a fonte de um ato e sim o alvo móvel de um amplo conjunto de entidades que enxameiam em sua direção" (LATOUR, 2013, p. 75). Nas palavras de Donna Haraway (2013, p. 3), estamos diante de "um bestiário de agências". Tais vínculos e movimentações conformam uma situação complexa e multiagentiva, relacionada a fluxos de movimentos, comunicações não verbais, influências mútuas entre os diferentes agentes envolvidos, "temporalidades mais-que-humanas" e "coordenação multiespécies"8.

A reflexão sobre as relações e os entendimentos mútuos entre botos e os pescadores teve início com uma discussão sobre comunicação interespecífica (CATÃO; BARBOSA, 2018). Com o tempo, a reflexão foi paulatinamente abandonando um entendimento de comunicação excessivamente associado a índices, sinais e trocas de mensagens, para assumir sentidos mais ligados às ideias de atração, corpos, movimentos, corresponsividades, temporalidades humanas e não humanas, ajustamentos rítmicos, coordenação e sintonização multiespécies. Dessa forma, o entrosamento e a sintonização entre botos, tainhas e pescadores (com a participação de ventos, fluxos d'água e artefatos) é mais próxima de uma dança rica em improvisações do que de um intercâmbio mais ou menos codificado de mensagens.

\section{Etoecologia, Organismos-em-seus-ambientes}

Botos bons e botas boas desenvolveram comportamentos raros ou pouco usuais, tanto em relação a indivíduos da mesma espécie quanto a outros membros da própria população. Tais comportamentos - tantas vezes pensados apenas em termos de capacidades morfológicas e cognitivas - jamais estão desconectados das relações desses animais específicos com outros seres e fenômenos, de dado ambiente, igualmente específicos. Tais comportamentos são sempre propiciados ou não, favorecidos ou não, pelas relações que determinados animais (humanos e não humanos) estabelecem uns com outros, em termos intra e interespecíficos, em um dado ambiente. Portanto, as noções de "organismosem-seu-ambiente" (BATESON, 1972) e "comunidades híbridas" (LESTEL; BRUNOIS; GAUNET, 2006) nos parecem bastante apropriadas para pensar o caso da pesca conjunta 8 Para as ideias de "temporalidades humanas e mais-que-humanas" e "coordenação multiespécies", ver Gan (2016) e
Gan e Tsing (2018). 
em Laguna. Quando nos referimos à determinada espécie, muito além de uma expressão em latim que classifica, descreve e tipifica uma classe particular de seres, diferentes animais (bem como vegetais, vírus, fungos e bactérias) são seres particulares, vivendo em meio a dinâmicas igualmente particulares que se desenvolvem, bem como o próprio ambiente, a partir de suas coconstituições, coabitações, coevoluções e influências mútuas.

O caso da gorila Koko também é exemplar nesse sentido. Koko e sua criadora codesenvolveram uma linguagem de sinais. Lestel et al. (2006, p. 161) afirmam o seguinte: "Nothing changed in the brain of Koko, the gorilla that learned a symbolic language. But the human/animal community in which she lived led her to acquire communication skills that do not spontaneously appear in her species".

Lestel, Bussolini e Chrulew (2014, p. 126) afirmam que "[...] se almejamos entender comportamentos animais pouco usuais, devemos descartar o hábito de pensar em termos de espécies em geral. Em vez disso, deveríamos pensar na singularidade dos animais [...]", sempre envolvidos em "comunidades híbridas" também singulares, eu acrescentaria.

Tais habilidades interespecíficas afloram em um meio concreto, em um ambiente específico. Na ecologia das práticas de Isabelle Stengers, um ethos - como uma maneira de se comportar própria de um ser - é inseparável do oikos - o habitat deste ser. No entanto, não é uma relação de dependência ou de determinação.

Quem diz inseparabilidade não diz dependência funcional. Uméthos não é uma função do seu meio ambiente, do seu oikos, ele sempre será o éthos do ser que se revela capaz dele. Nós não o transformaremos de modo previsível transformando o meio ambiente. (STENGERS, 2018, p. 449)

Nesse sentido, o habitat (oikos ou meio ambiente) pode ser pensado como um affordance, no sentido gibsoniano do termo - um "propiciador" - ver Gibson (1986). Aquilo que propicia, ou não, que determinados éthos e habilidades se desenvolvam. Ou seja, um ambiente é muito mais do que um cenário no qual a ação se desenrola.

Nós não sabemos do que um ser é capaz, do que pode se tornar capaz. O meio ambiente, poderíamos dizer, propõe, mas é o ser que dispõe dessa proposição, que lhe dá ou lhe nega uma significação "etológica" (STENGERS, 2018, p. 449, grifo meu).

Em sua ecologia das práticas, a autora recupera a ideia deleuziana de "pensar pelo meio" (STENGERS, 2017, p. 5). "Meio" pode significar tanto "entre" ("middle") quanto "ambiente" ("surroundings" ou "habitat") - meio ambiente ou oikos. A necessidade de "pensar pelo meio" significa tanto a ausência de referência a um objetivo basal ou ideal como a não separação de algo do meio do qual depende para existir.

"Through the middle" would mean without grounding definitions or an ideal horizon. "With the surroundings" would mean that no theory gives you the power to disentangle something from its particular surroundings, that is, to go beyond the particular towards something we would be able to recognise and grasp in spite of particular appearances. (STENGERS, 2005, p. 187)

Por isso, a ecologia de Isabelle Stengers é sempre uma etoecologia. Segundo a autora, não há "ecologia relevante" sem uma etologia (ou várias, eu diria) correlata, pois não há etologia independente de uma ecologia particular. Da mesma forma, ela dirá que não há "identidade de uma prática" independentemente de seu ambiente. O que, mais uma 
vez, não significa que a "identidade de uma prática" seja derivada de seu meio ambiente. "Thinking 'par le milieu' does not give power to environment" (STENGERS, 2005). A autora recorre a Spinoza para nos lembrar de que não sabemos do que uma prática é capaz de se tornar. O que sabemos é que uma prática é parte do ambiente (surroundings) que produz seu ethos. Durante muito tempo, me parecia incompreensível que houvesse tão poucas ocorrências de pescas colaborativas mundo afora. Afinal, tainhas, golfinhos nariz-de-garrafa e seres humanos são espécies cosmopolitas, encontradas em toda faixa temperada e tropical do planeta, coabitando vários lugares no globo. Pensando assim, eu estava concentrada demais nas espécies envolvidas, desconsiderando a relevância de um ambiente e uma história propiciadora.

As ideias de "etnoetologia", de "etoetnologia" (LESTEL et al., 2006) e de "etoecologia" (STENGERS, 2005) complementam-se de maneira exemplar. Se, na proposição de Lestel et al. (2006), a ênfase recai sobre as conexões entre animais humanos e não humanos, na concepção de Stengers (2005), o foco recai sobre as relações entre tais seres e seus habitats. A reunião dessas perspectivas abarca as conexões entre animais humanos e outros-que-humanos em um meio concreto.

Isabelle Stengers (2016, p. 175) nos ensina que "[...] o indivíduo isolado não é algo que tem um significado. Assim, a agência não pertence ao humano em si [ou a outros animais, eu acrescentaria], mas sempre ao humano [e a outros-mais-que-humanos] em um meio concreto". Em processos generativos como esse, cadeias multidirecionais de afecções, nas quais corpos afetam e são afetados por outros corpos, cumprem um papel fundamental. Portanto, muito mais do que nos perguntarmos sobre "quem são estes humanos e outros-que-humanos" envolvidos, talvez mais valha nos perguntarmos sobre "o que, juntos, eles fazem e 'fazem-fazer'? Como eles fazem e "fazem-fazer"? Como se tornam e fazem os demais se tornarem?". Nas palavras de Donna Haraway (2008, p. 3), "[...] how is 'becoming with' a practice of becoming worldly?".

\section{Reconhecimento e Sinalização}

As primeiras questões dirigidas aos pescadores na Tesoura tinham a ver com reconhecimento, tanto dos botos individualmente quanto de seus sinais sobre a localização dos cardumes. Como os pescadores identificavam cada um daqueles animais? Como eram os movimentos dos botos para mostrar peixe? Com o tempo, eu perceberia que ambas as perguntas estão interligadas, pois a capacidade de reconhecer os sinais dos botos tem a ver com conhecer bem quem os executa.

Inicialmente, tanto os botos quanto seus movimentos pareciam-me em tudo muito semelhantes. Todos os golfinhos possuíam uma coloração acinzentada que se misturava com a cor da água, enquanto os pescadores diziam que alguns botos eram mais branquicentos e outras bem pretinhas. Os movimentos corporais eram quase sempre semicirculares, acompanhados de expirações pelo orifício respiratório, gerando aquele característico borrifo d'água. Os pescadores, por seu turno, descreviam botos que saltavam mais riscado, outros que só faziam a volta, aqueles que eram mais calmos ou mais ladinos, mais sorrateiros ou violentos. Os golfinhos circulavam em pequenos ou grandes grupos e 
de tempos em tempos nos surpreendiam com a presença de um filhotinho. Era tudo o que eu via, de modo que, a princípio, a dinâmica da pesca soava bastante aleatória. Como aqueles pescadores reconheciam tantas descontinuidades naquela paisagem aparentemente tão contínua? Como eles destacavam tantas diferenças daquele fundo de aparente semelhança?

Em geral, da areia ou mesmo da linha d'água, visualizamos apenas partes dos corpos dos botos, sobretudo a nadadeira dorsal, cauda e cabeça. Borrifos d'água, partes do corpo, rastros dos movimentos. Os pescadores relacionam-se com índices daqueles animais no ambiente, tanto dos golfinhos quanto das tainhas. Estas últimas são reconhecidas por meio de restolhos e brilheiros (alterações de textura e reflexos na superfície da água) e também por meio do comportamento dos botos. Um boto, ou bôta boa, rodeando um alagado de pedras submerso ou cheirando peixe na pedra, é sinal da presença das tainhas por ali. Os pescadores, portanto, deduzem a localização e o comportamento dos cardumes por meio de sinais dos peixes na água, da movimentação indicial dos botos, mas também pelos regimes de ventos, épocas do ano e, em menor medida, pela presença de determinadas aves. Nesse sentido, aves, ventos e botos são como os tellers descritos pelos velhos aborígenes a Deborah Bird Rose (2013, p. 103): “Outra faceta da comunicação é que o mundo está cheio do que os antigos chamavam 'tellers'. 'Tellers' são aqueles que provêm informação: eles dão notícias do que está acontecendo no mundo".

Uma vez identificada a presença das tainhas no ambiente, resta aos pescadores saber o melhor momento de lançarem suas redes. Os sinais dos botos para mostrar peixe podem não ser nada óbvios, pois, aparentemente, tais movimentos não são completamente extraordinários em relação a outros movimentos mais ou menos corriqueiros desses animais. No entanto, os pescadores dizem que o salto do boto para mostrar o peixe é mais forte, agressivo, enérgico ou violento. A sinalização, portanto, é um movimento mais intenso por parte do golfinho em questão. Com o tempo, entende-se que cada boto ou bôta realiza tal movimento à sua maneira.

Gregory Bateson (1972) chama atenção para uma forma de comunicação baseada em sinais cinésicos e paralinguísticos, comum a todos os mamíferos (inclusive humanos) e também a outros animais. Chamada de comunicação analógica, e ostensiva, os sentidos dos sinais são determinados pelo contexto e, sobretudo, por variações de magnitude, isto é, diferenças de amplitude, intensidade, velocidade e/ou duração (BATESON, 1972, p. 378379; BATESON, 1979, p. 111). Em linhas gerais, tais sinais correspondem a movimentos e posturas corporais, tensões musculares; hesitações, pausas e acelerações; alterações de voz, respiração e expressão facial, entre outros9. É justamente o que se passa em Laguna. No entanto, é necessário ter prática e experiência para conseguir reconhecer tais variações.

\footnotetext{
Existe um vasto universo de formas de comunicações não-verbais muito pouco explorado pela antropologia, tradicionalmente concentrada na linguagem verbal humana (ver, por exemplo, Moore, 2010). Além da comunicação cinésica e paralinguística, podemos mencionar as comunicações háptica, relativa ao toque; cronológica, relativa à estrutura do tempo; e proxêmica, relativa ao uso do espaço social. Heine Hediger, biólogo considerado o "pai da zoobiologia", desenvolveu um vasto trabalho com proxêmica e arquitetura em zoológicos (Sebeok, 2001). A comunicação entre plantas e pessoas, através de sonhos, visões e ícaros, foi denominada comunicação trans-verbal e abordada por Callicot (2017). Por meio de uma outra abordagem, eco-semiótica, as relações dos seres humanos com as plantas, foram tratadas por Hornborg (2001). Já os fluxos semióticos inerentes aos processos fisiológicos do reino vegetal, foram designados como fito-semiótica e trabalhados por Kull (2000). Estes são apenas alguns exemplos. As comunicações não-verbais estendem-se ainda a habilidades extraordinárias. Algumas pessoas cegas, por exemplo, locomovem-se e identificam objetos, distâncias e até mesmo texturas em um ambiente, por meio de sonar e ecolocalização. Através de cliques (estalos) produzidos com a língua no céu da boca produzem sons que lhes devolvem imagens acústicas (Gonçalves e Thomé, 2011), em um processo semelhante àquele utilizado pelos golfinhos e pelos morcegos.
} 
A sinalização de um boto bom ou bôta boa não se resume a um movimento mais intenso por parte do animal, pois esse movimento é apenas o desfecho ou clímax de uma sequência de índices e de ações que começou muito antes dele. Os sinais espalhados no ambiente são muito mais abrangentes do que o salto final do boto. Quando esse movimento acontece, vários eventos significativos, "marcadores de contexto", já indicavam a presença dos peixes e a iminência do lanço. Em um lanço típico, os botos já se aproximaram, esperaram as tainhas deixar as pedras (cheiraram peixe, disfarçaram, boiaram de barriga para cima), afugentaram o cardume na direção dos pescadores (trancaram ou apertaram o peixe) para, finalmente, indicar sua localização. Portanto, reconhecer a sinalização de um boto bom ou de uma bôta boa inclui muitos outros (re)conhecimentos prévios. Dessa forma, os gestos para mostrar peixe não são particulares ao repertório total de movimentos desses animais, não constituem um repertório de movimentos excepcionais, mas possuem uma significação que é estabelecida por diferenças de contexto e magnitude.

\section{Multidirecionalidade}

Durante um bom tempo, eu reconhecia apenas dois atos como atos de sinalização: os movimentos corporais de botos e bôtas boas, indicativos da localização dos cardumes, e o gesto dos pescadores de bater a tarrafa na água. Mantive tal entendimento até o dia que ouvi: "se o boto mostrar o peixe uma, duas, três vezes, e o cara não botar a tarrafa, o boto larga o peixe". Claro. O ato de mostrar peixe não é uma sinalização unidirecional de botos para pescadores. A comunicação entre botos e pescadores depende de um feedback positivo dos pescadores. Ao lançar a tarrafa no local e no momento exatos, os pescadores também estão sinalizando para os botos que estão entendendo seus movimentos. Corresponsividade. Tal pesca conjunta só é possível, porque existe um engajamento responsivo de ambos os lados. "A troca material-semiótica entre Cayenne e eu não é um assunto unilateral" (HARAWAY, 2008, p. 206). A emissão recíproca de movimentos, sinais e feedback positivos, portanto, é o que garante os entendimentos mútuos, a reciprocidade e a continuidade da troca.

Além disso, quando assumem suas posições dentro d'água, os pescadores, intencionalmente ou não, sinalizam para os botos sua presença no canal e o intuito de pescar. Seus passos pelo banco de areia, a presença de seus corpos dentro d'água e sua movimentação acima e abaixo da superfície são notadas pelos golfinhos. Ou seja, a "simples" presença dos corpos dos pescadores dentro d'água é um ato comunicativo. Portanto, de saída, é preciso abandonar um entendimento de comunicação limitado à linguagem verbal, em prol de uma definição muito mais ampla, que abrange outros processos em que os seres se influenciam (voluntária ou involuntariamente, intencional ou não intencionalmente), por meio da presença de seus corpos, movimentos, posturas e/ou transmissão de alguma forma de sinal. Para a realização de uma pesquisa que envolve tão decisivamente animais não humanos, foi absolutamente fundamental o deslocamento da atenção da linguagem verbal para a presença, os movimentos, as ações e as suas influências mútuas. 
Botos, peixes e pescadores comportam-se de forma responsiva também em relação a fatores ambientais, como os fluxos hídricos do canal (marés e correntes) e a direção e intensidade dos ventos. Os movimentos ajustam-se mutuamente, configurando uma cadeia de ações circular e multilinear. Isso requer de botos, de bôtas e de pescadores uma aprendizagem mais complexa, genérica ou abstrata, que Gregory Bateson (1972) chamou de deuteroaprendizagem ou "aprender a aprender". O que implica responder de maneiras distintas aos "mesmos" sinais, conforme o contexto (BATESON, 1972, p. 279). Botos e pescadores não aprendem apenas a responder estímulos específicos de forma predeterminada, como nos casos de adestramento de animais. Eles aprendem a responder tais estímulos contextualmente. O que implica que não respondam sempre da mesma forma. No caso dos pescadores, eles precisam saber reconhecer os diferentes contextos e sinais, que tanto podem ser movimentos corporais de botos e cardumes quanto outras conjunturas ambientais (como a quadra de ventos recente, por exemplo). No caso dos botos, eles ajustarão seus comportamentos de acordo com a localização do cardume, direção e intensidade da corrente e movimento da maré, além de não responderem da mesma maneira a todos os lançamentos de tarrafa. Os pescadores contam que, dependendo das condições ambientais, os botos trabalharão em vagas (posições dos pescadores dentro d'água) diferentes. A relação "estímulo-resposta", portanto, não é automática ou préfixada. Tanto botos quanto pescadores aprendem a ser contextualmente responsivos aos estímulos uns dos outros e aos demais fatores ambientais. Nesse sentido, embora exista grande entendimento e entrosamento entre tarrafeadores e botos, não existe algo como uma convenção compartilhada entre eles, segundo a qual gestos determinados possuiriam significados preestabelecidos. Há sempre doses imprevistas de criatividade e de improvisação envolvidas e quanto mais experientes forem uns e outros, maior o repertório para criar e improvisar.

A sintonização, portanto, surge como a capacidade de atuarem de forma ajustadamente responsiva uns aos outros. Uma questão fundamentalmente relacionada à confluência de diferentes temporalidades, humanas e mais-que-humanas. "Através da diferença radical e além da intenção humana, emergem modos de coordenação criativa" (GAN, 2016, p. 8). Conforma-se, assim, uma situação de "coordenação multiespécies" entre diferentes ações e temporalidades. Cada lançamento de tarrafa de um pescador é, ao mesmo tempo, fruto e expressão dessa coordenação entre temporalidades diversas. Para cada lançamento de rede e captura de peixes, é preciso que diversos seres, fenômenos meteorológicos e artefatos estejam em "correspondência" (INGOLD, 2016).

"Pescadores de fora estragam o boto porque não tem experiência e o boto não gosta de quem tarrafeia na cega", relatou um tarrafeador à pesquisadora Deborah Peterson (2005, p. 32). Pescadores inexperientes não acertam o compasso entre reconhecer um sinal corretamente e lançar a tarrafa no momento e local indicados. Tais pescadores desconhecem o tempo, o ajuste rítmico correto e necessário para se pescar com os botos. Ao "tarrafearem na cega" - de forma aleatória, fora do tempo de sinalização do boto - tais tarrafeadores quebram a corresponsividade e, com isso, a possibilidade de sintonização e parceria. Sem corresponsividade e ajustamento rítmico, os botos não têm condição de desenvolver a habilidade necessária para a pesca conjunta. 
Da mesma maneira que há pescadores inexperientes, há botos inexperientes. Dizem os pescadores que os filhotes são pegos na tarrafa, porque, após a mãe sinalizar, eles apressadamente avançam na direção do cardume, e isso faz com que sejam enredados. $\mathrm{O}$ que sugere que os botos sinalizam e esperam a tarrafa cair na água, abrir-se dentro d'água como um balão, para, só então, se aproximarem, cavarem um peixe na tarrafa ou capturar um peixe em fuga. O emalhe do filhote inexperiente acontece, portanto, por falta de sintonização entre os movimentos de sinalização do boto, lançamento da rede pelo pescador, abertura da tarrafa e aproximação do boto para eventual captura do peixe. Assim como o pescador inexperiente, o filhote iniciante ainda não possui o tempo, a apuração rítmica correta e necessária para a boa dinâmica na pesca conjunta. Os botos são afobados, dizem os pescadores.

O tempo de abertura da tarrafa dentro d'água e os diversos movimentos envolvidos em seu manuseio - lançamento, recolhimento, arrasto, desmalhe dos peixes, limpeza e preparação para o próximo lance - participam decisivamente da temporalidade maisque-humana desta pesca. O modo de funcionamento da tarrafa é uma peça importante na engrenagem da dinâmica da pesca e na repetição dos ciclos de aproximação, cerco e sinalização dos botos, na eventual captura das tainhas e revezamento entre os pescadores. Desse modo, o funcionamento e a temporalidade da tarrafa são decisivas nesta pesca. Ouso dizer que essa pesca, que inclui os golfinhos se aproximarem e não se machucarem, só é possível porque a tarrafa é desacelerada. Também por isso, essa modalidade de pesca pode ser considerada, em uma expressão em inglês, como slow fishing.

Em sua pesquisa sobre falcoaria, Sara Schroer (2014) afirma que as condições climáticas, como uma atividade em andamento, influenciam os movimentos de animais humanos e não humanos e as maneiras como eles percebem o mundo. A autora chamou essa influência das condições climáticas sobre os movimentos de aves de rapina, falcoeiros e suas presas de weathering. No contexto de Laguna, de forma semelhante, "o vento sul faz o peixe correr, viajar" e a "quebra da maré é uma hora boa para peixe". Ou seja, as forças climáticas movimentam os corpos de animais humanos e não humanos e estes mesmos corpos e movimentos influenciam-se mutuamente.

A chegada dos botos no canal faz os pescadores entrarem na água. Enfileirados, com seus corpos dentro d'água, eles formam um anteparo, trabalham em equipes e tarrafeiam de modo coordenado, entre si e com os botos. As tainhas navegam e são capturadas em cardumes. As pedras formam aglomerados no fundo e nas laterais da lagoa. A saída das tainhas das pedras faz os botos afugentá-las em direção aos tarrafeadores. Os ventos formam quadras de vento e atuam em sequências e combinações. Os fluxos d'água, correntes e marés, combinam-se e revezam-se. Os golfinhos vivem em grupos. Um certo movimento por parte de algum boto ou bôta boa fará um pescador lançar sua rede. O lançamento de uma tarrafa propulsiona o arremesso daquelas do entorno. Uma rede cheia de peixes fará o tarrafeador sair da água e assim ceder sua vaga a outro que esperava. Nesse sentido, os conhecimentos necessários para a pesca conjunta, tanto por parte dos botos quanto dos pescadores, podem ser considerados um "conhecimento cinésico" (TSING, 2013) ${ }^{10}$. Há um encadeamento de ações e movimentos e cada variação ganha sentido em relação

\footnotetext{
10 Anna Tsing recorre à expressão "kinetic knowledge" para mencionar o conhecimento de coletores de cogumelos, referindo-
} se à navegação pela floresta e movimentação de seus corpos durante a coleta do matsutake. 
Águas de Dançar Juntos: Coordenação e Sintonização Multiespécies na Pesca com os Botos em Laguna ...

ao fluxo anterior e subsequente. Na dinâmica dessa pesca, trata-se menos de trocas de mensagens entre sujeitos individuais do que de sequências de ações e movimentos entre coletividades. Logo, subjetividades e perspectivas individuais importam menos do que as ações coletivas e os fluxos generativos.

Mesmo os marasmos e esperas, tão comuns nas pescarias, são repletos de acontecimentos. Enquanto "nada acontece" e os pescadores, a pesquisadora e os turistas, um tanto entediados, esperam por algo, o vento está ventando (ou não), a maré está enchendo ou vazando, as correntes marítimas estão correndo, as tainhas estão circulando, os golfinhos estão navegando, até o momento confluente em que o encontro entre eles acontece ${ }^{11}$. O movimento existe mesmo quando temos a sensação de que "nada está acontecendo". Para a ideia de weathering, portanto, eu acrescentaria algo como embodying, no sentido de "corporificação", pois, além das condições climáticas, os corpos e movimentos de uns geram e contêm os corpos e movimentos de outros. Embodying pode significar "dar uma forma tangível ou visível a algo" ou "incluir ou conter algo como uma parte constituinte". Ambos sentidos possuem significado aqui. "Dar uma forma visível ou tangível", "corporificar", um estímulo externo. Cada corpo e movimento inclui ou contêm outros corpos e outros movimentos, como partes constitutivas de si mesmo. Nos termos de Vincianne Despret (2004), isso seria algo como antropozoogênese.

Figura 4 - Captura

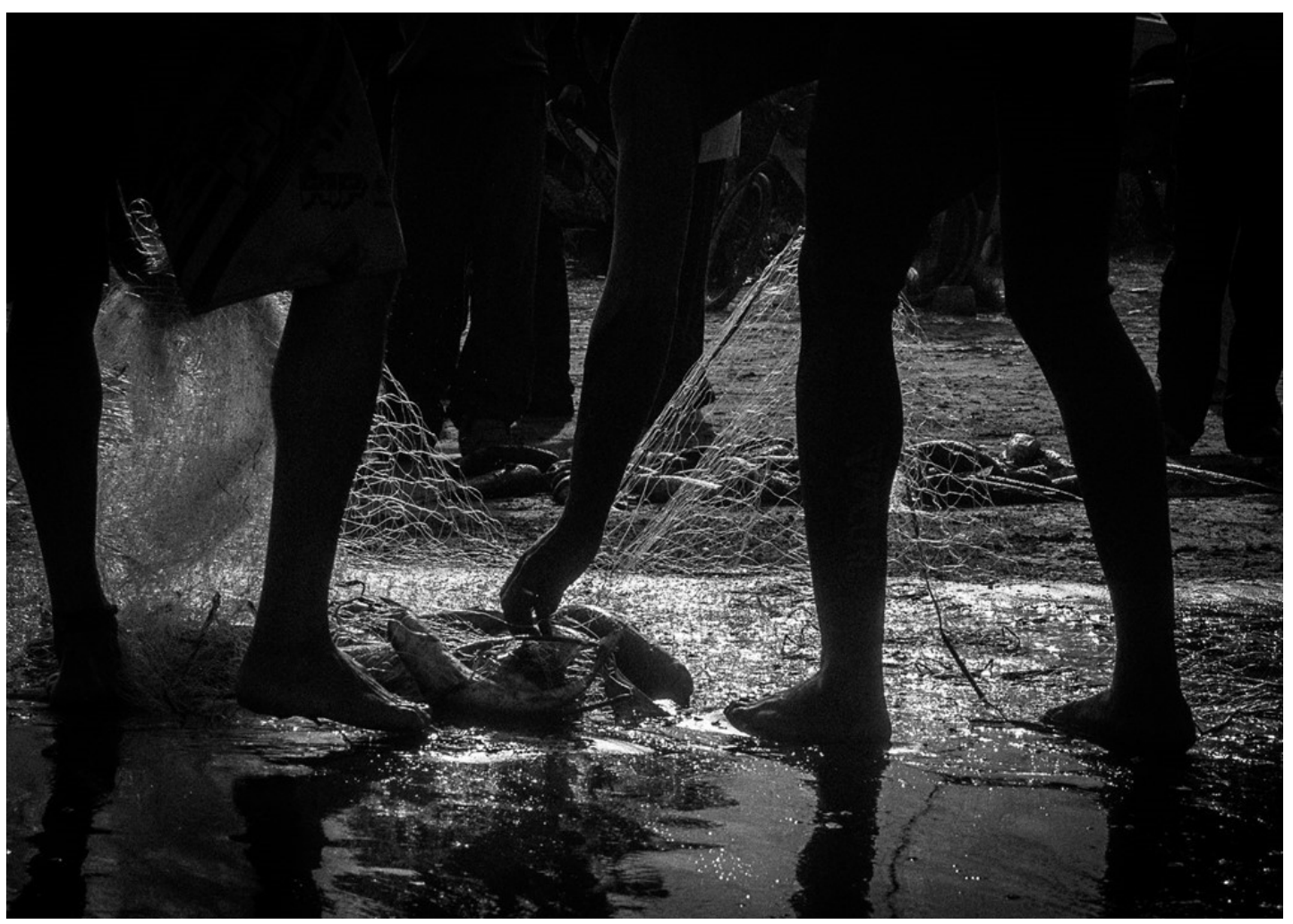

Fonte: Acervo pessoal de Brisa Catão

Portanto, não é uma troca ou composição interespecífica baseada em uma linguagem verbal, mas em uma sintonização e coordenação corresponsiva de diferentes corpos, ritmos,

11 Para a ideia de "confluência", ver Antônio (Nego) Bispo dos Santos (2015). 
Águas de Dançar Juntos: Coordenação e Sintonização Multiespécies na Pesca com os Botos em Laguna ...

movimentos e temporalidades humanas e mais-que-humanas. Como os movimentos de uns geram os movimentos de outros? Quais os efeitos de suas ações nas ações dos demais? A ideia foi criar imagens da corresponsividade, da coordenação e da sintonização entre peixes, botos, pescadores, artefatos e forças climáticas.

Figura 5 - Porquinho no Cais

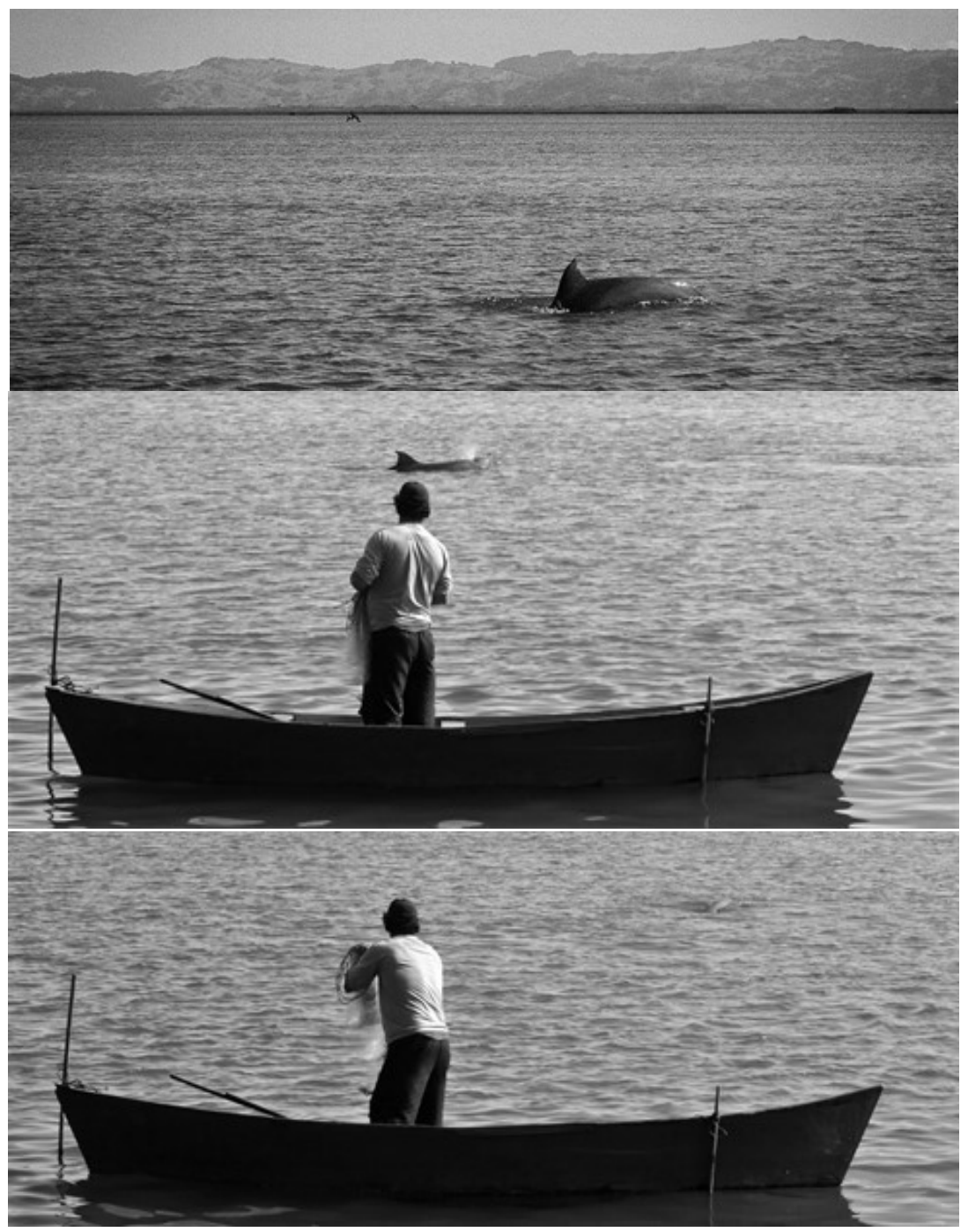

Fonte: Acervo pessoal de Brisa Catão

Nas palavras de Starhawk (2018, p. 55), “[...] a natureza canta e fala, e o mundo inteiro se comunica conosco. Nisso, podemos reconhecer outra definição de magia: a magia seria a arte de se abrir e ouvir profundamente essa comunicação".

\section{Referências}

BATESON, Gregory. Steps to an ecology of mind. Collected essays in anthropology, psychiatry, evolution, and epistemology. Northvale, NJ: Jason Aronson Inc., 1972.

BATESON, Gregory. Mind and nature: a necessary unity (advances in systems theory, complexity, and the human sciences). New York: Hampton Press, 1979. 
BITARÃES, Adriano. Livro Infinito. [s.l.: s.n.], 2021. (no prelo).

BOCCHINO, R. Pesca Artesanal com o Auxílio dos Botos em Laguna. BRA, 2015. Documentário. Duração: 16min53seg. Disponível em: https://www.youtube.com/ watch?v=8uqC34gMZOA. Acesso em: 10 jan. 2021.

CADORÍN, A.; CADORÍN, L. Laguna Terra Mater: dos sambaquis à República Catarinense. Blumenau: Nova Letra, 2013.

CALLICOT, C. Comunicação entre Espécies na Amazônia Ocidental Caderno Chão da Feira, [s.l.], n. 71, 2017.

CATÃO, Brisa. Impressões na Água: peixes, botos e pescadores na pesca conjunta em Laguna. 2019. 183p. Tese (Doutorado) - Universidade Federal de Minas Gerais, Belo Horizonte, 2019.

CATÃO, Brisa; BARBOSA, C. G. Botos Bons, Peixes e Pescadores: sobre a pesca conjunta em Laguna (Santa Catarina, Brasil). Revista do Instituto de Estudos Brasileiros, [s.l.], v. 69, p. 205-225, 2018.

DAURA-JORGE, Fábio G. Quantos? Onde? Como? Múltiplos aspectos ecológicos de uma população do boto-da-tainha (Tursiops truncatus) em Laguna, sul do Brasil: implicações para conservação. 2011. 264p. Tese (Doutorado em Zoologia) - Programa de PósGraduação em Ciências Biológicas, Zoologia, Universidade Federal do Paraná, Curitiba, 2011.

DESPRET, V. The body we care for: Figures of anthropozoo-genesis. Body and Society, [s.l.], v. 10, n. 2-3, p. 111-134, 2004.

GAN, Elaine. Time Machines: Making and Unmaking Rice. 2016. Dissertation (Doctor of Philosophy) - University of California, Santa Cruz, 2016.

GAN, Elaine; TSING, Anna. How things hold. A Diagram of Coordination in a Satoyama Forest. Social Analysis, [s.l.], v. 62, p. 102-145, 2018.

GIBSON, James. The ecologycal approach to visual perception. New York: Psychology Press, 1986.

GONÇALVES, A.; THOMÉ, C. Cegos usam técnica para "ver" com audição. O Estado de São Paulo, São Paulo, 2011. Disponível em: https://www.estadao.com.br/noticias/geral,cegosusam-tecnica-para-ver-com-audicao-imp-,740066. Acesso em: 2 mar. 2020.

HARAWAY, Donna. O Manifesto das Espécies de Companhia: cães, pessoas e a outridade significante. 2013. Disponível em: https://www.academia.edu/37220573/Manifesto_das_ Especies_de_Companhia. Acesso em: 30 nov. 2020.

HARAWAY, Donna. When Species Meet. Minneapolis: University of Minnesota Press, 2008.

HERZING, D. Could we speak the language of dolphins? 2013. Duração: 14min38seg. Disponível em: https://www.ted.com/talks. Acesso em: 2 jan. 2019.

HORNBORG, A. Vital signs: an ecosemiotic perspective on the human ecology of Amazonia. Sign Systems Studies, [s.l.], v. 29, p. 121-152, 2001.

INGOLD, Tim. On Human Correspondence. Journal of the Royal Anthropological Institute, [s.l.], v. 0, p. 1-19, 2016.

KULL, K. An introduction to phytosemiotics: Semiotic botany and vegetative sign systems. Sign Systems Studies, [s.l.], v. 28, p. 326-350, 2000.

LATOUR, Bruno. Faturas/Fraturas: da noção de rede à noção de vínculo. Ilha - Revista de Antropologia, Florianópolis, v. 17, n. 2, 2015.

LATOUR, Bruno. Reagregando o social: uma introdução a teoria do Ator-Rede. Salvador, BA, Edufba; Edusc, 2013. 
LESTEL, D.; BRUNOIS, F.; GAUNET, F. Etho-ethnology and ethno-ethology. Social Science Information, [s.l.], v. 45, n. 2, p. 155-177, 2006.

LESTEL, D.; BUSSOLINI, J.; CHRULEW, M. The Phenomenology of Animal Life.

Environmental Humanities, [s.l.], v. 5, n. 1, p. 125-148, 2014.

MOORE, Nina. Nonverbal Communication: studies and applications. New York: Oxford University Press, 2010.

PETERSON, D. Etnobiologia dos botos (Tursiops truncatus) e a pesca cooperativa em Laguna, Santa Catarina. 2015. 74p. Monografia (Bacharelado em Ciências Biológicas) Universidade Federal de Santa Catarina, Florianópolis, 2005.

PETERSON, D.; HANAZAKI, N.; SIMÕES-LOPES, P. C. Natural resource appropriation in cooperative artisanal fishing between fishermen and dolphins (Tursiops truncatus) in Laguna, Brazil. Ocean Coast Manag. [s.l.], v. 5, p. 469-475, 2008.

PRYOR, Karen. et al. A dolphin-human fishing cooperative in Brazil. Marine Mammalogy Science, [s.l.], n. 6, p. 325-332, 1990.

ROHR, João Alfredo. Sítios Arqueológicos de Santa Catarina. Anais do Museu de Antropologia da UFSC, Florianópolis, 1984.

ROMEU, B. Contribuições do comportamento acústico do boto-da-tainha (Tursiops truncatus) para o entendimento da interação entre botos e pescadores em Laguna, Santa Catarina. 2015. 100p. Dissertação (Mestrado em Ecologia) - Universidade Federal de Santa Catarina, Florianópolis, 2015.

ROMEU, B. Repertório acústico do boto-da-tainha no contexto da pesca cooperativa com pescadores artesanais em Laguna, sul do Brasil. 2012. 62p. Monografia (Bacharelado em Ciências Biológicas) - Universidade Federal de Santa Catarina, Florianópolis, 2012.

ROSE, D. B. Val Plumwood's Philosophical Animism: attention interactions in the sentient world. Environmental Humanities, [s.l.], v. 3, p. 93-109, 2013.

SANTOS, Antônio (Nego) Bispo. Colonização, Quilombos: modos e significados. Brasília: INCTI, 2015.

SEBEOK, Thomas. The Swiss Pioneer in Nonverbal Communication Studies: Heini Hediger (1908-1992). New York: Legas, 2001.

SHOROER, Sara. On the Wing. Exploring Human Bird Relationship in Falcoery Practice. 104. Thesis for Philosophy in Anthropology - University of Aberdeen, Scotland, 2014.

SIMÕES-LOPES, P. C. Interaction of coastal populations of Tursiops truncates (Cetacea, Delphinidae) with the mullet artisanal fisheries in southern Brazil. Biotemas, [s.1.], 1991.

SIMÕES-LOPES, P. C.; DAURA-JORGE, F. G. Os parceiros da sobrevivência. Insular, Florianópolis, v. 4, n. 2, p. 83-94, 2008.

SIMÕES-LOPES, P. C.; DAURA-JORGE, F.; CANTOR, M. Clues of cultural transmission in cooperative foraging between artisanal fishermen and bottlenose dolphins, Tursiops truncatus (Cetacea: Delphinidae). Zoologia, [s.l.], v. 33, n. 6, 2016.

SIMÕES-LOPES, P. C.; FÁBIAN, M. E. Residence patterns and site fidelity in Bottlenose Dolphins, Tursiops truncatus (Cetacea, Delphinidae) of Southern Brazil. Rev. Bras. de Zool., [s.l.], v. 16, n. 4, p. 1.017-1.024, 1999.

SIMÕES-LOPES, P. C.; FÁBIAN, M.; MENEGUETI, J. O. Dolphin interactions with the mullet artisanal fishing on Southern Brazil: a qualitative and quantitative approach. Revista Brasileira de Zoologia, [s.l.], n. 15, p. 709-726, 1998. 
STARHAWK. Magia, Visão e Ação. Revista do Instituto de Estudos Brasileiros, [s.l.], Tradução de Adriana Rinaldi e Jamille Pinheiro Dias, n. 69, p. 52-65, 2018.

STENGERS, I. A proposição cosmopolítica. Revista do Instituto de Estudos Brasileiros, Brasil, n. 69, p. 442-464, 2018.

STENGERS, I. An Ecology of Practices. Cultural Studies Review, [s.l.], v. 1 l, n. 1, 2005.

STENGERS, I. Uma ciência triste é aquela em que não se dança. Rev. Antropol. [s.l.], v. 59, n. 2, 2016.

STENGERS, I. Reativar o Animismo. Cadernos Chão de Feira, [s.l.], n. 62, 2017.

TSING, Anna. Dancing the Mushroom Forest. PAN: Philosophy, Activism, Nature, [s.l.], n. 10, 2013.

\section{Brisa Catão}

Doutora em Antropologia Social pela Universidade Federal de Minas Gerais. Mestre em Antropologia Social pelo Programa de Pós-Graduação em Antropologia Social da Universidade Federal de Santa Catarina, em 2013, e Bacharel em Ciências Sociais pela Universidade Federal de Minas Gerais em 2008. Endereço profissional: Programa de Pós-Graduação em Antropologia (Mestrado e Doutorado) Av. Antônio Carlos, n. 6.627, FAFICH,sala 4228, Campus Universitário, Belo Horizonte, MG. CEP 31270-901. E-mail: brisacatao@gmail.com

ORCID: https://orcid.org/0000-0002-9292-3683

\section{Como referenciar este artigo:}

CATÃO, Brisa. Águas de Dançar Juntos: Coordenação e Sintonização Multiespécies na Pesca com os Botos em Laguna ( SC - Brasil). Ilha - Revista de Antropologia, Florianópolis, v. 23 , n. 1, p. 30-49, janeiro, 2021. 